\title{
A GEOPOLÍTICA DO ESPAÇO CIBERNÉTICO SUL-AMERICANO: (IN) CONFORMAÇÃO DE POLÍTICAS DE SEGURANÇA E DEFESA CIBERNÉTICA?'
}

\section{Selma Lúcia de Moura Gonzales ${ }^{2}$ \\ Lucas Soares Portela ${ }^{3}$}

\section{Introdução}

O chamado espaço cibernético é o ambiente onde informações de todos os matizes, quer econômicos, sociais, políticos ou militares, sejam dados sigilosos ou não, trafegam e se interconectam. É também o ambiente onde se estabelecem acordos, compras e vendas, legais ou ilegais e manipulações diversas, sejam de dados ou de informações.

Nesse contexto, não é possível escrever sobre segurança e/ou defesa sem vincular essas temáticas ao espaço cibernético e sobre a complexidade que o envolve: os crimes, os delitos, os roubos, os domínios, os controles e as próprias relações de poder que se estabelecem nesse espaço, em outras palavras, sem estar atento a uma geopolítica do espaço cibernético.

$\mathrm{O}$ ambiente regional sul-americano vem sendo analisado comumente sob vários ângulos e temáticas por pesquisadores de diversos países da região, especialmente, no contexto de fóruns regionais, a exemplo da Organização dos Estados Americanos, numa regionalização mais ampla, ou ainda no âm-

I Este artigo foi elaborado a partir de um working paper apresentado no $6^{\circ}$ Encontro da Associação Brasileira de Relações Internacionais, de 25 a 28 de julho, em Belo Horizonte, MG. 2 Professora na Escola Superior de Guerra - Campus Brasília. Doutora em Geografia pela Universidade de São Paulo - selmagonzales@esg.br

3 Mestre em Ciências Militares pela Escola de Comando e Estado-Maior do Exército -lucas. portela@hotmail.com 
A geopolítica do espaço cibernético Sul-americano: (in) conformação de políticas de segurança e defesa cibernética?

bito da União de Nações Sul-Americanas (UNASUL), sob a perspectiva do continente Sul-Americano. Temas diversos como direitos humanos, cooperação regional, fortalecimento da democracia, povos indígenas, desenvolvimento sustentável, promoção da paz, dentre tantos outros, fazem parte da agenda de pesquisa. No que se refere, especificamente, à temática do espaço cibernético, apenas mais recentemente, no final da década de I990, surgem iniciativas na OEA e, no princípio da atual década, houve um debate mais específico na UNASUL.

Na OEA, a preocupação inicial era combater os delitos cibernéticos e suas ações estavam vinculadas aos Ministérios da Justiça dos países membros. Num segundo momento, já na década de 2000 , após o atentado terrorista de II de setembro, a preocupação foi criar, em 2004, uma Estratégia Interamericana Integral de Segurança Cibernética, enfocando, além dos delitos, os crimes, os ataques e o terrorismo.

No âmbito da UNASUL, o primeiro movimento com relação à temática do espaço cibernético ocorreu em 20I2, por ocasião da formulação, pelo Conselho de Defesa Sul-americano (CDS), de um plano de trabalho, onde previa a criação de um grupo de trabalho para avaliar a possibilidade de estabelecer políticas e mecanismos regionais para combater as ameaças cibernéticas ou informáticas no âmbito da defesa (Unasul 2012).

Ainda que esses fóruns regionais apresentem iniciativas para elaborar políticas e estratégias ligadas à segurança e defesa cibernética, cada país membro acaba estabelecendo suas políticas de maneira independente. Por vezes, a própria definição dos conceitos de segurança e defesa no que se refere ao espaço cibernético não são similares entre os países, assim como suas respectivas políticas e seus órgãos responsáveis.

Nesse sentido, este artigo se propõe a analisar as iniciativas políticas e as estruturas voltadas à segurança e defesa cibernética no espaço sul-americano, tomando como estudo de caso três países sul-americanos com maior densidade de internautas - Argentina, Brasil e Colômbia - situando essas políticas no contexto de dois fóruns regionais: Organização dos Estados Americanos (OEA) e a União de Nações Sul-Americanas (UNASUL), e, a partir da análise dessas políticas, verificar se existe uma similaridade e interlocução entre elas, ou se são dissonantes, se podemos considerar que está em processo uma configuração geopolítica do espaço cibernético na região que influencia na conformação de poder regional.

Para a elaboração desta pesquisa, realizamos um levantamento das principais políticas de segurança e defesa cibernética a partir de dados coletados em fontes primárias, tais como leis, decretos, resoluções, declarações e atas publicadas nos fóruns regionais e nos países pesquisados, além de fontes

218 Austral: Revista Brasileira de Estratégia e Relações Internacionais v.7, n.14, Jul./Dez. 2018 
secundárias por meio de bibliografia especializada.

Estruturamos este artigo em cinco partes. Inicialmente, faremos uma breve discussão conceitual sobre a geopolítica do espaço cibernético; em seguida, apresentaremos algumas considerações sobre espaço cibernético, segurança e defesa; depois mostraremos as iniciativas com relação ao espaço cibernético gestadas no âmbito da OEA e da UNASUL; além das especificidades do espaço cibernético nas políticas de defesa e segurança da Argentina, Brasil e Colômbia. Por fim, o artigo apresentará algumas considerações sobre a geopolítica do espaço cibernético na América do Sul, enfocando o posicionamento desses países com relação a estruturas institucionais, esferas de atuação e políticas de cooperação.

\section{A Geopolítica do Espaço Cibernético}

Antes de refletir sobre uma possível geopolítica do espaço cibernético na América do Sul, faz-se necessário explicitar a perspectiva teórica que ora estamos assumindo, assim como a proposição adjetiva do conceito de geopolítica para o espaço cibernético. Nesse sentido, a primeira questão que se coloca é sobre a legitimidade do uso de um campo de conhecimento voltado, a priori, ao espaço territorial para se referir ao espaço virtual.

Sob a perspectiva ontológica do neologismo "geopolítica" criado em I899 pelo professor de Teoria do Estado na Universidade de Uppsala, Rudolf Kjellén, não seria possível vincular geopolítica e espaço cibernético, haja vista o sentido fundante do conceito, o estudo dos fenômenos políticos influenciado pelo solo (situação geográfica, espaço ocupado e domínio territorial, consubstanciado em seus recursos a ser explorado). Ao elaborar sua teoria, Kjellén concebia um espaço essencialmente continental, quiçá marítimo, haja vista sua preocupação com o território estatal como um organismo ligado ao solo e em constante luta por mais espaço.

Todavia, ao estudarmos fenômenos políticos, necessariamente, analisamos relações de poder e, nesse sentido, o campo de conhecimento da geopolítica carrega, em sua essência, análises sobre relações de poder e espaço. Não obrigatoriamente só o espaço estatal, premissa fundamental da geopolítica tradicional, conforme nos esclarece Heriberto Carou $(2002,206)$

La reflexión espacial sobre las relaciones de poder no se puede limitar --como ocurría en la Geopolítica tradicional - a las existentes entre los Estados; olvidaría entonces los innumerables flujos que ocurren al margen; operaría de forma reduccionista limitando «lo político» a «lo estatal». De este modo, 
A geopolítica do espaço cibernético Sul-americano: (in) conformação de políticas de segurança e defesa cibernética?

aunque la Geopolítica crítica hace hincapié en la microescala de análisis (la que se ocupa del planeta entero), como era el caso en la tradicional, esto no puede significar el abandono de otras escalas, a riesgo de caer en un determinismo geográfico4. (grifo nosso) (Carou 2002, 206)

Nesse sentido, consideramos que as relações de poder operam em diversas escalas e dimensões, assim como apenas são colocadas em funcionamento no contexto espacial, em outras palavras, o poder necessita de um espaço para existir, pois não pode operar ou ser exercido no vácuo, considerando que é sempre relacional. Não há poder se não há objeto referente, pois esse se exerce sempre em relação a algo ou a alguém.

Se no conceito de geopolítica de Kjellén estava subjacente a relação política e espaço, então essas duas dimensões necessitam ser consideradas quando das análises geopolíticas na contemporaneidade: a política (poder) e o espaço (geográfico) onde ocorre. Nesse sentido, quais espaços podem ser considerados?

$\mathrm{Na}$ atual conjuntura, novos espaços se apresentam como locus onde as relações de poder acontecem, assim como outros atores, além do estatal, participam desse jogo. Dessa maneira, a análise geopolítica incorpora novas dimensões espaciais, outros atores e poderes diversos.

Assim, o espaço cibernético se apresenta como mais um locus onde as relações de poder (política) ocorrem. Poderíamos considera-lo como mais um espaço geográfico? Quais categorias e elementos constitutivos esse "espaço virtual" comporta para que possa ser considerado um espaço geográfico?

Para Walfredo Ferreira Neto (20I4, 79 - 85), o espaço virtual tem seu controle realizado pelos atores mais aptos, apesar de ser visto como um espaço global e comum, por isso passa a ser territorializado. Prossegue o autor: "no ambiente cibernético do globo, os Estados definem seus territórios [...]. Como exemplos imediatos, mas não únicos, tem-se os domínios dos sítios “.br”; “.us"; “.uk"; “.it”;..., que indicam perfeitamente os respectivos territórios"

Nos elementos constituintes do espaço cibernético existem as fronteiras, que, segundo Ferreira Neto $(2014,70)$ devem ser vistas na forma de ponto, que pode ser ao mesmo tempo uma informação em seu "pacote", ou um "nó" de uma infovia, ou, ainda, uma estrutura estratégica ou infraestrutura crítica

\footnotetext{
4 A reflexão espacial sobre as relações de poder não pode limitar-se, como ocorria na Geopolítica tradicional, às existentes entre os Estados; pois, desconsideraria, assim, os inumeráveis fluxos que ocorrem à margem e operaria de forma reducionista limitando o político ao estatal. Desse modo, ainda que a Geopolítica crítica saliente a microescala de análise (a que se ocupa do planeta inteiro), como era o caso na geopolítica tradicional, isso não pode significar o abandono de outras escalas, pois se corre o risco de cair em um determinismo geográfico.
}

220 Austral: Revista Brasileira de Estratégia e Relações Internacionais v.7, n.14, Jul./Dez. 2018 
selecionada graças ao aos recursos disponíveis ao Estado.

Se aceitarmos a existência de um espaço geográfico cibernético, então é possível falar de uma geopolítica cibernética, com características específicas em cada local e conforme os atores envolvidos e as políticas que o gerencie, assim como conflitos, delitos, crimes, políticas e estratégias elaboradas com o intuito de, ora gerir, ora proteger, expandir, atacar, ou seja, políticas e relações de poder no e para o espaço cibernético.

\section{Espaço Cibernético, Segurança e Defesa: algumas conside- rações}

Durante a história, encontramos diversos exemplos de civilizações que valorizavam o discurso e seu estudo, como por exemplo, quando Roma era um império. A importância desse exercício era tamanha para algumas civilizações que elas estudavam o discurso por meio da oratória e retórica, como faziam os atenienses.

Por meio desses estudos, se lia não somente o conteúdo, mas também os interesses e intenções do seu autor. Embora uma política não seja um discurso, ao analisarmos podemos compreender valores e interesses dos agentes do jogo político (Serafim and Dias 20I2). Cabe salientar, no entanto, que estamos falando de análise de políticas e não de sua avaliação.

Embora ambos os termos pareçam sinônimo e possam ser aplicados às políticas, o foco e resultado gerado são distintos (Serafim and Dias 20I2). Uma avaliação consiste em observar os resultados que determinada política gera, verificando sua eficiência diante de dado problema. No caso deste artigo, não pretendemos olhar os resultados das políticas de defesa cibernética da Argentina, Brasil e Colômbia, mas os interesses, posições e interações desses países, por isso, analisar e não avaliar.

Dito isso, uma análise de políticas deve observar três níveis (página seguinte): 
A geopolítica do espaço cibernético Sul-americano: (in) conformação de políticas de segurança e defesa cibernética?

Quadro 1 - Níveis de Análises de Políticas

\begin{tabular}{|l|l|}
\hline \multicolumn{1}{|c|}{ Níveis de análises } & \multicolumn{1}{c|}{ Descrição } \\
\hline Institucional & $\begin{array}{l}\text { Observa as interações dentro da(s) institui- } \\
\text { ção(ões) envolvidas. Este nível observa o processo } \\
\text { decisório dentro da organização, como também } \\
\text { as relações que ela mantém. }\end{array}$ \\
\hline Processo decisório & $\begin{array}{l}\text { Nesse nível observam-se os interesses dos } \\
\text { agentes envolvidos, assim como a reação deles a } \\
\text { estímulos internos e externos. }\end{array}$ \\
\hline Relação Estado-Sociedade & $\begin{array}{l}\text { Observa as regras e instituições do Estado. A } \\
\text { relação de poder dentro delas e a interação dessas } \\
\text { estruturas com a sociedade. Esse nível interliga } \\
\text { os outros dois níveis, demonstrando os interes- } \\
\text { ses por de trás das políticas empregadas. }\end{array}$ \\
\hline
\end{tabular}

Fonte: Dagnino (2002).

As políticas de defesa geralmente consideram também o ambiente internacional como motivador, a análise política deve abarcar um nível de Cenário Internacional. Esse deveria considerar as relações de poder existente, tanto no âmbito regional como global, a posição do país no cenário internacional, especialmente em algumas temáticas, assim como os conflitos existentes, em síntese, uma análise geopolítica do Cenário Internacional. Esse nível ganha mais destaque dentro da temática do espaço cibernético, que apresenta características transfronteiriças.

Para poder aplicar a análise proposta no início do tópico, devemos primeiramente distinguir a defesa e segurança cibernética. A separação desses conceitos pode nortear a análise quanto à política adotada. Cabe ressaltar, entretanto, que esse é um exercício analítico no nível ontológico, pois no espaço cibernético os conceitos se interconectam. (Portela 20I5).

Conforme Paulo Carvalho (20II), a defesa cibernética pode ser definida como o conjunto de ações realizadas no espaço cibernético, visando à defesa de sistemas e informações. Por essa perspectiva, a defesa cibernética apresenta valor na integridade da força, especialmente no que tange a produção de conhecimento e inteligência. Cabe ressaltar, que esse autor inclui não somente ações defensivas na defesa cibernética, mas também ações exploratórias e ofensivas.

Por sua vez, a segurança cibernética é associada por Oscar Medeiros Filho (20I4) à dimensão da segurança pública. Para esse autor, a defesa cibernética está ligada a noção de guerra, enquanto a segurança cibernética está 
associada à ideia de ilícitos. Assim, de acordo com ele, a conceituação de segurança e defesa cibernética vincula-se a ameaça que está se combatendo.

Moisés Naím (2006) aborda a questão num sentido similar, quando discorre sobre os limites dos conceitos de segurança e defesa tradicional. Sobre esses dois conceitos Naím (2006) infere que a defesa tem relação com guerra, defesa de interesses nacionais, garantia da sobrevivência e da soberania, enquanto a segurança pública tem relação com questões de ilícitos. Assim, para distinguir segurança e defesa cibernética precisamos identificar o que são delitos cibernéticos.

Estes podem ser categorizados em dois grupos: crimes cibernéticos e ataques cibernéticos (Portela 20I5). De acordo com McGuire and Dowling (20I3), a categorização desses conceitos deve ser realizada por meio da analogia e aplicabilidade no ambiente tradicional. Exemplificando, uma extorsão online é um crime cibernético, enquanto o roubo de dados de uma base militar é considerado um ataque cibernético, por ser um ato de espionagem e guerra.

Feitas as distinções conceituais, podemos categorizar as organizações de defesa cibernética, de maneira geral, por meio de um plano cartesiano, em que um eixo apresenta escala gradativa quanto a distinção do conceito de segurança e defesa cibernética e no outro a classificação quanto a natureza da organização. Em um estremo, observamos estruturas que tratam os temas de segurança e defesa cibernética com separação total e na outra extremidade as que integram os temas ao ponto de abordá-los como sinônimos. Quando classificamos as instituições da América do Sul nesse plano, encontramos o seguinte desenho:

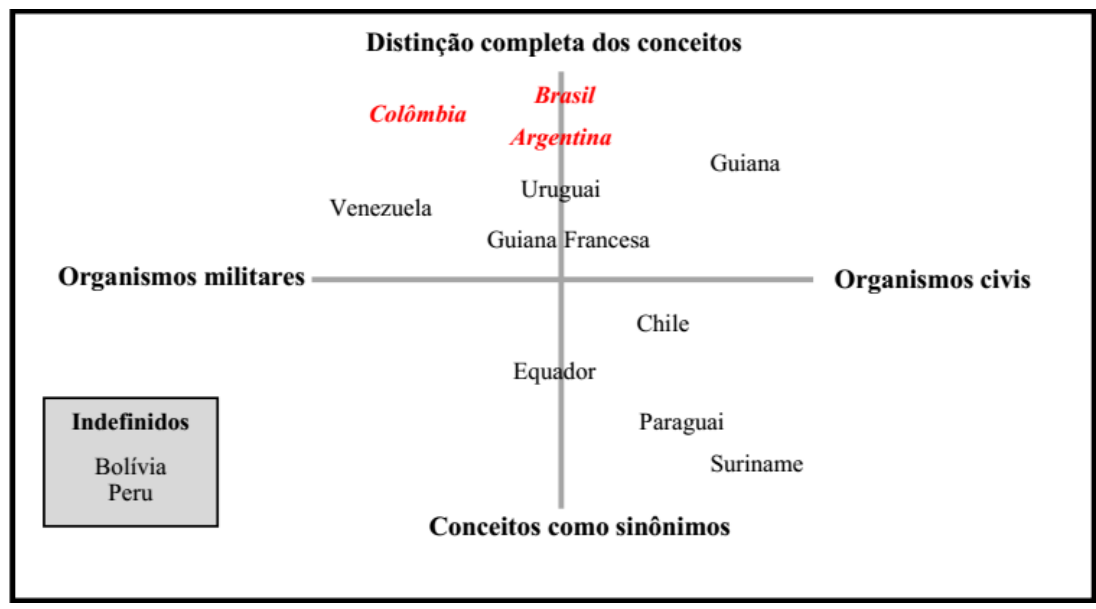

Figura 1 - Extrato das organizações de defesa cibernética da América do Sul (2016) 
A geopolítica do espaço cibernético Sul-americano: (in) conformação de políticas de segurança e defesa cibernética?

Fonte: Elaboração própria, baseada em Argentina (2010), Justribó et al (2014), Mandarino Jr. e Canongia (2010), Brasil (2012; 2013; 2015), Conpes (2011), Chile $(2010 ; 2014)$, Paraguai $(2013 ; 2015)$, Equador $(2008 ; 2014)$, Uruguai $(2005 ; 2014)$, França $(2013 ; 2015)$ e Ministére de la Défense (2014; 2014b), Ministerio de Defensa (2015), Télam (2015), Contardo (2015), Velázquez (2015), Bonilla (2013), Infodefensa (2015) e IITCUP (2016).

A Bolívia e o Peru foram postos como indefinidos por não haver uma caracterização formal, por meio de documentos e estruturas, que vise a defesa ou segurança cibernética. A Argentina, Brasil e Colômbia aparecem em destaque na figura acima por serem objetos desta pesquisa, que apresentam similaridades, por tratar os conceitos de segurança e defesa cibernética de modo distinto.

A maior divergência que podemos observar nesse grupo diz respeito as estruturas específicas para o tratamento dos delitos cibernéticos. Colômbia apresenta estruturas puramente militares, enquanto Brasil e Argentina têm formação hibrida, com organismos militares e civis, tratando de defesa cibernética e segurança cibernética, respectivamente. A distinção da organização entre Argentina e Brasil está na interação entre as duas esferas. Embora o Brasil apresente organismos que se comuniquem, a interação é limitada a consultas mútuas.

\section{Espaço Cibernético no âmbito dos fóruns regionais}

No âmbito dos fóruns regionais americanos, apresentaremos um breve panorama de como a temática do espaço cibernético é tratada em dois deles: OEA e UNSAUL. Ainda que a proposta da análise seja, prioritariamente, a América do Sul, é importante situarmos a região também no contexto de um fórum hemisférico, haja vista a dupla vinculação dos países Sul-americanos.

\section{O Espaço Cibernético e a OEA}

No âmbito da OEA, a primeira iniciativa para tratar de temas vinculados ao espaço cibernético foi a criação de um Grupo de Trabalho em Delito Cibernético, discutida no foro chamado "Reunião de Ministros de Justiça ou Outros Ministros, Procuradores ou Fiscais Gerais das Américas (REMJA)".

Esse grupo, composto por especialistas de governos, se propunha a realizar diagnósticos sobre as atividades ilícitas ocorridas nas redes de computadores, a identificar a legislação, as políticas e as práticas nacionais relativas a essas atividades e as identidades nacionais e internacionais que tivesse ex-

224 Austral: Revista Brasileira de Estratégia e Relações Internacionais v.7, n.14, Jul./Dez. 2018 
periência na matéria, além de identificar mecanismos de cooperação dentro do sistema interamericano para combater o delito cibernético. (OEA/REMJA I999) $)^{5}$

Após a criação do Grupo de Trabalho em Delito Cibernético da REMJA, em I999, ocorreram reuniões regularmente, com uma periodicidade que variava entre dois ou três anos. A nona e mais recente reunião ocorreu em 2016.

Para facilitar e tornar mais eficiente a cooperação e o intercâmbio de informações entre os especialistas cibernéticos governamentais dos Estados membros da OEA, foi criado um portal na internet ${ }^{6}$, onde são listadas as legislações dos países relativas à temática, as recomendações advindas de cada reunião do Grupo de Trabalho, além da proposição de uma "Rede de Contatos sobre Delitos de Alta Tecnologia 24 horas/7 dias", com o objetivo de compartilhar e denunciar delitos cibernéticos em cooperação internacional, envolvendo outros países externos à OEA, tais como tais como as Nações Unidas, a União Europeia, o Foro de Cooperação Econômica Ásia-Pacífico, a OCDE, o G-8, a Commonwealth e a INTERPOL. Porém, ainda que as proposições nesse sentido remontem às recomendações resultantes da reunião do ano 2000 , na reunião de 20ı6, ainda se orientavam aqueles países que ainda não haviam aderido a essa rede que o fizesse no menor prazo possível.

Os objetivos do Grupo de trabalho em Delito Cibernético continuam sendo:

Fortalecer la cooperación internacional en la investigación y persecución del delito cibernético, facilitar el intercambio de información y de experiencias entre sus integrantes y formular las recomendaciones que sean necesarias para mejorar para mejorar y fortalecer la cooperación entre los Estados miembros de la OEA y con otras organizaciones o mecanismos.

5 "En vista de la importancia y la dificultad de las cuestiones que plantea el delito cibernético y la difusión y magnitud potencial de los problemas que presenta para nuestros países, recomendó el establecimiento de un grupo de expertos gubernamentales en el marco de la OEA con el siguiente mandato:

a) Hacer un diagnóstico de la actividad delictiva vinculada a las computadoras y la información, o que utiliza las computadoras como medio para cometer un delito;

b) hacer un diagnóstico de la legislación, las políticas y las prácticas nacionales con respecto a dicha actividad;

c) identificar las entidades nacionales e internacionales que tienen experiencia en la materia; $\mathrm{e}$

d) identificar mecanismos de cooperación dentro del sistema interamericano para combatir el delito cibernético." (OEA/REMJA I999)

6 Para mais informações sobre o Portal, consulte http://www.oas.org/juridico/spanish/ cybersp.htm. 
A geopolítica do espaço cibernético Sul-americano: (in) conformação de políticas de segurança e defesa cibernética?

(OEA 2OI7)

Todavia, paralelamente à existência desse Grupo, cujo foco era apenas delitos cibernéticos, em 2003 foi publicada a AG/RES. I939 (XXXIII-O/03) "Desarrollo de una estrategia interamericana para combatir las amenazas a la seguridad cibernética", resolução aprovada na quarta sessão plenária, em Io de junho de 2003.

Nessa resolução, foi encomendado ao Conselho Permanente que por meio da Comissão de Segurança Hemisférica se desenvolvesse um projeto de estratégia de segurança cibernética para os Estados Membros, em coordenação e colaboração com o Comitê Interamericano contra o Terrorismo (CICTE), a Comissão Interamericana de Telecomunicações (CITEL) e o Grupo de Especialistas Governamentais sobre Delito Cibernético da Reunião de Ministros de Justiça ou de Ministros ou Procuradores Gerais das Américas (REMJA), ou outro órgão apoiado pela OEA. Assim, foi proposto um projeto de estratégia integral que abordasse os aspectos multidimensional e multidisciplinar da segurança cibernética. (OEA 2003)

Em 2004, por meio da aprovação da AG/RES. 2004 (XXXIV-O/O4) pela Assembleia Geral, foi adotada a "Estrategia Interamericana Integral de Seguridad Cibernética: un Enfoque Multidimensional y Multidisciplinario para la Creación de una Cultura de Seguridad Cibernética" e instado a que os países integrantes da OEA implementassem as diretrizes constantes dessa estratégia. (OEA 2004)

Dentre essas diretrizes, estava a orientação para que os países membros estabelecessem ou identificassem grupos nacionais de "vigilância e alerta", os chamados "Grupos de Resposta a Incidentes de Segurança em Computadores” (CSIRT). Também, a formação de uma Rede Interamericana de Vigilância e Alerta para a rápida divulgação de informação sobre segurança cibernética e a resposta a crises, incidentes e ameaças à segurança informática, além de buscar fomentar o desenvolvimento de uma cultura que permitisse o fortalecimento da segurança cibernética no Hemisfério.

Se a criação do Grupo de trabalho para Delito Cibernético foi pensado ainda na década de I990 e tinha como foco a criação de uma rede voltada para fazer frente a temas ligados à delinquência cibernética, por outro lado, a proposta de criar uma Estratégia Integral de Segurança Cibernética em 2003, já era o resultado das iniciativas pensadas em um mundo pós-ataque terrorista de II de setembro de 200I. A preocupação naquele momento era não apenas com delitos, mas uma estratégia que envolvesse ameaças terroristas ciber- 
néticas, ataques a infraestruturas críticas ${ }^{7}$, dentre outras preocupações. Cabe salientar que na criação do Grupo de Trabalho para Delito, em I999, não se mencionava a expressão "infraestrutura crítica".

Tanto a criação do Grupo de Trabalho sobre Delito em I999 quanto a Estratégia Interamericana Integral de Segurança Cibernética, aprovada em 2004, não conseguiram uma efetiva participação de todos os países membros da OEA. As recomendações contidas na nona Reunião do Grupo de trabalho em Delito Cibernético, a mais recente, instavam os países que cumprissem várias diretrizes do Grupo, dentre essas, seis que ainda não haviam sido atendidas pelos estados, por exemplo, com relação a criação de uma rede: "los Estados que aún no lo han hecho, en el menor plazo posible, consideren la posibilidad de vincularse a la "Red de Contactos sobre Delitos de Alta Tecnología 24 horas/7 días" del G-7." Com relação à Estratégia Interamericana Integral, de 34 (trinta e quatro) países membros, apenas i7 (dezessete), ou seja, a metade apresentava Centros de Estudos, Respostas, Tratamentos de Incidentes de Segurança (CERT) ou Grupo de Resposta a Incidentes de Segurança em Computadores (CSIRT), órgãos que a própria OEA sugeria como necessários e incentivava sua criação nos países membros. Dos I7 (dezessete) países que têm CERT ou CSIRT, II (onze) integram a UNASUL: Argentina, Colômbia, Bolívia, Brasil, Chile, Equador, Guiana, Paraguai, Peru, Suriname, Uruguai e Venezuela. Os demais são Canadá, EUA, Guatemala, México, Panamá, Trinidad e Tobago.

Analisando as ACTAS Y DOCUMENTOS da Assembleia Geral da OEA (textos certificados das Declarações e Resoluções), a partir da aprovação da Estratégia Integral de 2004, constatamos que a temática da segurança cibernética aparece vinculada ao terrorismo (2005 e 20II), às telecomunicações (2006) e estratégias no âmbito da Comunidade do Caribe /CARICOM (20IO, 2013 е 2016).

O que nos parece é que após o escândalo de espionagem do governo brasileiro pelos EUA, vindo a tona em agosto de 2013 , divulgado pelo americano ex-consultor técnico da Agência Central de Inteligência (CIA) dos Estados Unidos (EUA), Eduardo Snowden, houve o fortalecimento de um movimento surgido em 20I2, no contexto da UNASUL, para a criação de grupo de trabalho sobre a temática, com foco na defesa cibernética, uma iniciativa que ocorre

\footnotetext{
7 Desarrollaremos una cultura de seguridad cibernética en las Américas adoptando medidas de prevención eficaces para prever, tratar y responder a los ataques cibernéticos, cualquiera sea su origen, luchando contra las amenazas cibernéticas y la delincuencia cibernética, tipificando los ataques contra el espacio cibernético, protegiendo la infraestructura crítica y asegurando las redes de los sistemas. (OEA 2004, I29)
} 
A geopolítica do espaço cibernético Sul-americano: (in) conformação de políticas de segurança e defesa cibernética?

em paralelo às existentes no âmbito da OEA, arrefecendo as iniciativas que envolvessem mais diretamente o Brasil nesse organismo regional.

\section{O Espaço Cibernético e a UNASUL}

O primeiro registro da preocupação da UNASUL com as temáticas do espaço cibernético foi em 20I2, por ocasião da formulação, pelo Conselho de Defesa Sul-americano (CDS), de um plano de trabalho para aquele ano. Dentre os pontos previstos no plano, a UNASUL assinalou a necessidade de criação de um grupo de trabalho para avaliar a possibilidade de estabelecer políticas e mecanismos regionais para combater as ameaças cibernéticas ou informáticas no âmbito da defesa (Unasul 20I2). O responsável pela condução desse grupo seria o Peru.

No ano seguinte, 2013, o plano de trabalho não mais trazia a necessidade de avaliação da possibilidade de estabelecer política, mas o estabelecimento efetivo dela e também de mecanismos regionais para combater as ameaças cibernéticas no âmbito da defesa (Justribó 20I4). Nota-se, por meio desses dois documentos que a UNASUL iniciou suas propostas de defesa cibernética distinguindo ameaças cibernéticas de ameaças informáticas. Além disso, esses documentos enfatizam o combate das ameaças no âmbito da defesa, ou seja, distingue esse conceito daquele de segurança cibernética.

Naquele mesmo ano, a necessidade dessa organização em tratar de defesa cibernética aumentou perante uma ameaça real sofrida pelo Brasil, ao descobrir espionagem cibernética por parte dos Estados Unidos, já mencionada anteriormente. Tal ocorrido gerou uma menção especial durante a VII Reunião ordinária de chefes de Estados, em agosto de 2013:

Instruye al Consejo de Defensa Suramericano (CDS) y al COSIPLAN, evaluar la cooperación con otros consejos ministeriales competentes y avanzar en sus respectivos proyectos sobre defensa cibernética y la interconexión de las redes de fibra óptica de nuestros países, con el objetivo de tornar nuestras telecomunicaciones más seguras. Promover el desarrollo de tecnologías regionales y la inclusión digital. (Unasul 2013) ${ }^{8}$.

\footnotetext{
8 Instrui o Conselho de Defesa Sul-americano (CDS) e o COSIPLAN, avaliar a cooperação com outros conselhos ministeriais competentes e avançar em seus respectivos projetos sobre defesa cibernética e a interconexão das redes de fibra óptica dos nossos países, com o objetivo de tornar nossas telecomunicações mais seguras, fortalecer o desenvolvimento de tecnologias regionais e promover a inclusão digital. [tradução nossa].
}

228 Austral: Revista Brasileira de Estratégia e Relações Internacionais v.7, n.14, Jul./Dez. 2018 
Embora não tenha uma ligação direta com a experiência brasileira, a declaração final dessa reunião demonstra a urgência de fomentar a cooperação na temática de defesa cibernética no âmbito da UNASUL. Nesse caso, não se falou apenas da cooperação entre os membros da organização, mas estendeu a sinergia proposta para outros organismos regionais. Percebe-se que a securitização do tema trouxe para o documento da VII reunião ações mais concretas, como a interconexão das redes de fibra ótica e a coordenação do CDS e do Conselho Sul-americano de Infraestrutura e Planejamento (COSIPLAN) para fomentar uma infraestrutura conjunta (Unasul 20I3).

O encontro de agosto, que ocorreu no Suriname, foi o ponto inicial para que os trabalhos em prol da defesa cibernética fossem mais concretos. No plano de trabalho de 20I4 previu o Seminário Regional de Ciberdefesa (Justribó 20I4). Nesse evento, o Grupo de Trabalho de Defesa Cibernética do CDS identificou quatro pontos a seguir:

I. Crear un foro regional del Grupo de Trabajo de Ciberdefensa de los Estados Miembros, a fin de intercambiar conocimientos, experiencias y procedimientos de solución.

2. Establecer una red de contactos de autoridades competentes para el intercambio de información y colaboración de manera permanente.

3. Definir la plataforma y procedimientos de comunicaciones de la red de contactos.

4. Profundizar y sistematizar la reflexión sobre definiciones conceptuales de ciberdefensa y ciberseguridad. (Unasul 20I4) ${ }^{9}$

O fruto dessa agenda foi a criação de uma rede contatos dos representantes de cada país para tratar do assunto, que se comunicaria por correio eletrônico e telefonia. O grupo também concordou com a necessidade de se criar uma plataforma de coordenação que se chamaria UNACERT. Por último, requisitou que todos os países enviassem suas nomenclaturas, conceitos e terminologias de defesa cibernética e segurança cibernética para um debate, compilação e padronização conceitual.

Ainda hoje essas demandas e as novas requisições fazem parte da agenda do Grupo de Trabalho de Defesa Cibernética da UNASUL. Na ata da

9 I. Criar um foro regional do Grupo de Trabalho de Defesa Cibernética dos Estados Membros, a fim de trocar conhecimentos, experiências e procedimentos de soluções. 2. Estabelecer uma rede de contatos de autoridades competentes para a troca de informações e colaboração de maneira plena. 3. Definir a plataforma e procedimentos de comunicações da rede de contatos. 4. Produzir e sistematizar a reflexão sobre definições conceituais da defesa cibernética e segurança cibernética. [tradução nossa]. 
A geopolítica do espaço cibernético Sul-americano: (in) conformação de políticas de segurança e defesa cibernética?

I Reunião Virtual do grupo de março de 20I7, o grupo elencou seis pontos de trabalhos que ainda são semelhantes aos debates anteriores:

- Diagnóstico situacional por país e/ou da região, que estabelecerá o ponto de partida comum para o trabalho do grupo;

- Subsídio sobre a conceituação de defesa cibernética e segurança cibernética;

- Identificação de instituições, terminologias e protocolos que se utilizam em nível regional;

- Diagnóstico sobre o contexto das ameaças, atores e motivações regionais;

- Definição de espaços para discussão e definição de propostas: foros, redes, plataformas, observatórios etc.;

- Proposta de Políticas e Estratégias regionais de defesa cibernética, que serão apresentadas ao CDS-UNASUL para consideração e que serão elevadas a instância máxima da organização regional. (Unasul 20I7).

Percebemos que as medidas e o andamento de 2013 e 2014 foram consequência de um aquecimento momentâneo dos debates sobre defesa cibernética, que apesar dos frutos gerados, não satisfizeram a agenda da época. Além disso, notamos que o debate acerca da padronização dos conceitos e termos de defesa cibernética e segurança cibernética ainda é uma urgência, necessária para se propor políticas comuns a todos os membros. Apesar de ainda não tratar adequadamente essas questões, notamos que a UNASUL entende distintamente os dois conceitos, bem como também entende a necessidade de padronização as estruturas de defesa cibernética.

\section{Espaço Cibernético nas Políticas de Defesa e Segurança da Argen- tina, Brasil e Colômbia}

Não há uma homogeneidade no espaço cibernético Sul-Americano, no que se refere às políticas e estruturas institucionais, assim como na abordagem sobre o conceito segurança e defesa cibernética e as perspectivas com que são tratados ${ }^{10}$. Por vezes, tanto a segurança quanto a defesa cibernética

\footnotetext{
io Entre los desafíos que deberá enfrentar la agenda del Consejo de Defensa Suramericano, en materia de ciberdefensa, están las distintas percepciones de los países sobre la utilización de los medios militares y de seguridad interior. Estas concepciones, sobre los temas de seguridad y defensa, afectan a los distintos marcos normativos y doctrinarios que rigen los sistemas de seguridad interior y defensa nacional entre los países miembros de Unasur, por lo que la coherencia en el enfrentamiento de las cuestiones tocantes a la ciberseguridad y la ciberdefensa se difculta.(Bustamante, Rivera and Cañas 2015, Iı2)
}

230 Austral: Revista Brasileira de Estratégia e Relações Internacionais v.7, n.14, Jul./Dez. 2018 
são considerados por uma estrutura militar de defesa, ou em casos específicos, há uma estrutura civil e outra militar.

No âmbito da OEA, as políticas e diretrizes estão estruturadas com foco na segurança cibernética e envolve dois mecanismos: um que trata dos delitos cibernéticos, vinculado ao Departamento de Cooperação Jurídica, Secretaria de Assuntos Jurídicos e Reunião de Ministros de Justiça ou outros Ministros, Procuradores ou Fiscais Gerais das Américas (REMJA) e outro que cuida da segurança cibernética, a Estratégia Interamericana Integral para Combater as Ameaças à Segurança Cibernética, ligada ao Comitê Interamericano contra o Terrorismo (CICTE) e à Comissão Interamericana de Comunicações (CITEL).

Nesse sentido, a OEA enfoca o espaço cibernético especialmente sob a ótica da segurança e parece-nos que sua preocupação central é manter uma estrutura para fazer frente a delitos e crimes cibernéticos, inseridos nesse conjunto o terrorismo, além de não utilizar a nomenclatura "defesa cibernética".

Na esfera da UNASUL, pelo que constatamos, os trabalhos têm como foco a defesa cibernética. A proposta, em 20I2, de criação de um Grupo de Trabalho foi no sentido de avaliar a possibilidade de estabelecer políticas e mecanismos regionais para combater as ameaças cibernéticas ou informáticas no âmbito da defesa. Dentre as iniciativas, uma preocupação inicial foi a compreensão e a padronização de terminologias na temática da segurança e defesa cibernética. Também, a realização de diagnósticos situacionais nos países membros para identificar as particularidades estruturais e institucionais na área cibernética para, posteriormente, elaborar proposta de políticas e estratégias regionais de defesa cibernética e apresentar ao CDS-UNASUL.

Embora as ações nesta instituição sejam incipientes no que se refere ao espaço cibernético e estão ainda no nível do diagnóstico e padronização de terminologias, é possível afirmar que a preocupação maior é a defesa cibernética, diferente das iniciativas no âmbito da OEA, que tem por foco a segurança cibernética.

Com relação aos três países analisados, a Colômbia trata segurança e defesa cibernética em uma única esfera: a da defesa, o que pode gerar incompatibilidade conceitual ao integrar uma estratégia política conjunta com outros países da região. Acreditamos que tal fato vincula-se à necessidade histórica de combate aos grupos armados locais, buscando sua desarticulação, além do combate aos delitos cibernéticos.

No caso argentino, a defesa cibernética está sob a responsabilidade da estrutura militar, que também presta suporte à segurança cibernética e se 
A geopolítica do espaço cibernético Sul-americano: (in) conformação de políticas de segurança e defesa cibernética?

vincula a órgão civis.

No Brasil, as ações relativas à defesa cibernética estão sob a responsabilidade do Comando de Defesa Cibernética, subordinado ao Ministério da Defesa, enquanto aspectos vinculados à segurança cibernética governamental estão na estrutura do Gabinete de Segurança Institucional, órgão do poder executivo, ademais a existência de diversos entes privados responsáveis pela segurança cibernética, por meio de departamentos de segurança da informação ou de informática Esses órgãos apresentam sinergia com os organismos de defesa cibernética brasileira.

Brasil e Argentina apresentam agendas semelhantes, principalmente em termos de abrangência, já que seus órgãos de defesa cibernética englobam vários níveis do planejamento estratégico.

Das análises realizadas, não vislumbramos entre os três países analisados uma disputa de poder ou domínio cibernético. As políticas estão mais voltadas a questões intramuros e procuram atender as especificidades sociais, políticas e econômicas de cada país. Por outro lado, não há ainda uma conformação efetiva entre essas políticas, o que fragiliza a cooperação com reflexos para o fortalecimento da defesa e segurança cibernética na região sul-americana.

Ainda que esses países estejam inseridos em dois fóruns regionais (OEA e UNASUL), todavia, as políticas e iniciativas nesses fóruns parecem seguir roteiros paralelos, com enfoques e objetivos distintos, e não uma conformação ou convergência de diretrizes e aspirações.

No que se refere à cooperação entre os países analisados, as ações ainda estão em fases de declarações e apresenta como característica central a troca de conhecimentos.

A Argentina demonstrou sua intenção em cooperar na temática da defesa cibernética no ano de 20I3. Em Buenos Aires, durante um encontro entre os ministros da defesa da Argentina e do Brasil, Augustín Rossi e Celso Amorim firmaram uma declaração sobre a cooperação em defesa entre os dois países. A declaração teve como objetivo reiterar a necessidade de uma integração bilateral para a promoção da integração regional como consolidadora de uma zona de paz (Brasil 20I3).

A defesa cibernética também foi abordada na declaração, principalmente em um início de cooperação bilateral entre esses países para essa temática, conforme trecho abaixo:

Coincidieron en la necesidad de impulsar la cooperación en defensa cibernética y creación de un subgrupo de trabajo bilateral en el tema. Acord-

232 Austral: Revista Brasileira de Estratégia e Relações Internacionais v.7, n.14, Jul./Dez. 2018 
aron además organizar durante este año una visita a Brasil de autoridades argentinas en ciberdefensa con fines de conocer el Centro de Defensa Cibernética del Ejército Brasileño y celebraron la invitación que el Ministro de Defensa de Brasil realizó para que Argentina designe participantes es el Curso de Guerra Cibernética para Oficiales (20I4) y pará Suboficiales (20I5), en Brasil (Brasil 2013a, O2) ${ }^{\mathrm{II}}$.

A relação entre Argentina e Brasil para a defesa cibernética foi desenhada inicialmente como ações de conhecimento mútuo e geração de confiança entre ambos os lados. Nela não foram previstas ações de criações conjuntas, mas apenas de visitas e participações em cursos. Por isso, podemos afirmar que a Declaração de Buenos Aires sobre Defesa de 2013 apenas possibilitou uma aproximação da temática de defesa cibernética entre os dois países.

Isso é patente quando observamos as demais ações previstas nessa declaração. O documento pode ser dividido em reconhecimentos de trabalhos em cursos ou promovidos e previsões de ações futuras. Nas demais temáticas, as ações futuras previam aprofundamento de relações conjuntas práticas já estabelecidas, como por exemplo, a criação de Normas de Elaboração e Publicação de Doutrinas Combinadas entre os dois países (Brasil 2013a).

No ano seguinte, a Argentina também firmou declaração que envolvia a temática de defesa cibernética com o Chile. Diferente da declaração com o Brasil, esta estabeleceu ações conjuntas e práticas, com a criação de um Grupo Bilateral para aprofundamento da cooperação em assistência militar emergencial (Defensa Sur 20I4). Além disso, a declaração previu a criação de uma força binacional que poderá ser acionada em situações emergenciais.

Cabe ressaltar que longe de tentar um aumento de capacidades militares, a Argentina utiliza dos acordos de defesa para aproximar-se dos demais Estados sul-americanos. O diálogo bilateral, nessa perspectiva, poderia servir como uma base para uma integração regional, pois fomentaria a paz na região. Entretanto, tais declarações ainda não apresentam uma aplicação prática no âmbito da defesa cibernética, além das trocas de informações e interação entre os recursos humanos dos países envolvidos.

Entretanto, essa política vem sendo reorientada atualmente. Com a saída do governo de Cristina Kirchner e o início do governo Mauricio Macri,

II Concordaram na necessidade de impulsionar a cooperação em defesa cibernética e criação de um subgrupo de trabalho bilateral no tema. Acordaram também em organizar durante este ano uma visita ao Brasil de autoridades argentinas em defesa cibernética com fins de conhecer o Centro de Defesa Cibernética do Exército Brasileiro e celebrar o convite que o Ministro da Defesa do Brasil realizou para que a Argentina designe participantes para o Curso de Guerra Cibernética para Oficiais (20I4) e para suboficiais (20I5), no Brasil. (Brasil 2013a, 02) 
A geopolítica do espaço cibernético Sul-americano: (in) conformação de políticas de segurança e defesa cibernética?

os esforços de cooperação em defesa cibernética têm direcionamento para os Estados Unidos. O que fundamenta a ideia de que a cooperação em defesa é utilizada pela Argentina como uma ferramenta de governo e não como um projeto de Estado.

Em 20I7, por exemplo, durante visita do presidente argentino aos Estados Unidos, esses governos anunciaram a criação de um Grupo de Trabalho Intergovernamental Bilateral sobre Política Cibernética (Argentina 20I7). O grupo deve identificar vulnerabilidades cibernéticas de interesse mútuo aos dois países, assim como o desenvolvimento de iniciativas conjuntas. Cabe ressaltar que o anúncio não envolve somente a defesa cibernética, mas também a segurança cibernética.

Outra diferença deste grupo de trabalho para as declarações realizadas no âmbito da América do Sul é que além de impulsionar a temática entre os dois países, ele prevê ainda a cooperação em fóruns internacionais pertinentes à temática. Isso porque esses países entendem que a segurança do espaço depende dos demais atores internacionais (Argentina 20I7).

No caso brasileiro, a cooperação em defesa cibernética apresenta as duas direções, articulações intrarregionais e extrarregionais. Em ambos os casos, podemos inferir que o Brasil apresenta o mesmo modelo de cooperação estabelecido na já citada cooperação com a Argentina. Assim, o país busca enfatizar bilateralmente a importância desse espaço, criando subgrupos de trabalho na temática e estabelecendo mecanismos para a troca de conhecimento.

Além da Argentina, o Brasil já estabeleceu essas categorias de cooperação com o Chile, Alemanha e México (Oliveira et al. 20I7). No caso da Argentina, o subgrupo de trabalho vem se reunindo para tratar dos aspectos da defesa cibernética (Brasil 20I5a). Apesar disso, a cooperação ainda persiste no âmbito dos recursos humanos, dessa vez prevendo a realização de estágios na área da defesa cibernética (Brasil 20I5a).

A cooperação extrarregional realizada pelo Brasil no âmbito da defesa cibernética cresceu junto com a cooperação intrarregional. Em 20I4, o país firmou acordo com a Suécia. Naquela ocasião, esses países firmaram o compromisso de realizarem reuniões de trabalhos para tratar das temáticas de defesa. A segunda reunião de trabalho aconteceu no ano seguinte em Estocolmo. Entre a primeira edição e a segunda edição das reuniões de cooperação esses países realizaram diversas trocas de experiências na temática de defesa cibernética. No último estágio dessa cooperação, uma delegação sueca visitou o Centro de Defesa Cibernética do Exército Brasileiro (CDCiber) (Soares 20I6).

Ainda seguindo a linha do intercambio de conhecimento, o Brasil fir- 
mou acordo com a Índia em 2015. Com o Exército, foi previsto a realização de um curso internacional de Estudos Estratégicos em 2016, intercâmbio de professores e pesquisadores em segurança e defesa cibernética e cursos doutrinários nestas duas temáticas. Cabe ressaltar que mais que uma declaração de intenções, o encontro com os indianos gerou propostas acordadas no âmbito das três forças singulares.

Outra categoria de cooperação internacional do Brasil, em que a defesa cibernética tem sido alvo são aqueles relacionados a desastres naturais. Em 20I3, por exemplo, o país firmou acordo com a Espanha sobre essa temática. A temática de desastres naturais foi apontada pelo lado espanhol como objeto de aproximação com nações sul-americanas, que foi recebida pelo lado brasileiro como um tema a ser tratado primeiramente em nível bilateral (Brasil 20I3b).

No mesmo encontro, o Ministro de Defesa espanhol Morenés também demonstrou a preocupação espanhola com as questões inerentes à defesa cibernética. O então Ministro da Defesa, Celso Amorim, descreveu a experiência brasileira com o CDCiber e propôs a troca de informações como eixo inicial de cooperação (Brasil 20I3b). Assim, em termos gerais o Brasil trabalha a defesa cibernética com outros países dentro da ideia de intercambio de conhecimento, principalmente no que diz respeito à experiência brasileira com o CDCiber.

Vale citar ainda a reunião entre Brasil e Colômbia ocorrida em $20 \mathrm{I} 2$. Naquela ocasião, os países concordaram em criar uma Comissão Conjunta para revisar as capacidades das forças (El Tiempo 20I2). Composta por técnicos das forças armadas, avaliaria também a defesa cibernética de ambos os países (El Tiempo 20I2).

A Colômbia apresenta um perfil diferente do Brasil e Argentina no que tange a cooperação em defesa cibernética. A cooperação colombiana se dá principalmente em âmbito multilateral, especialmente no fórum da OEA. Nessa, a Colômbia recebeu missão que verificou a situação do espaço cibernético colombiano além de avaliar as capacidades desse país em defesa cibernética (OEA 20I4).

No eixo bilateral, a Colômbia tem uma cooperação com a Coreia do Sul, iniciado em 20I4. Diferente dos demais acordos e declarações já discorridas, a matéria dessa cooperação são as Tecnologias de Informação e Comunicação (TICs). Além de enfatizar a segurança cibernética e o governo eletrônico, este acordo ainda prevê a transferência de tecnologia (Mintic 20I5). Cabe ressaltar que a Colômbia lida com a temática de segurança e defesa cibernética na mesma esfera militar, portanto uma cooperação em segurança cibernética impacta diretamente na defesa cibernética. 
A geopolítica do espaço cibernético Sul-americano: (in) conformação de políticas de segurança e defesa cibernética?

Dentre os frutos dessa cooperação está o portal do governo eletrônico colombiano, o sistema de autenticação eletrônica e o fortalecimento de capacidades técnicas em resposta a incidentes e ameaças cibernéticas (Mintic 20I5). Além disso, também gerou a criação de um centro de armazenamento de dados para o governo colombiano, um curso avançado de resposta a incidentes cibernéticos e um estudo de modelo estratégico e operacional do ecossistema de segurança cibernética do país (Mintic 2015).

Em síntese, os acordos e declarações de cooperação em defesa cibernética ainda estão em fases iniciais. A cooperação é abordada no contexto da troca de conhecimento e intercâmbio de agentes de defesa cibernética, com exceção da Colômbia que apresenta um acordo com a Coreia do Sul com ações pontuais previstas. Assim, a cibernética é considerada dentro de um espectro amplo da defesa nacional e é utilizada ainda ora como uma ferramenta de aproximação ou ainda como um instrumento político.

\section{Espaço Cibernético nas Políticas de Defesa e Segurança da Argen- tina, Brasil e Colômbia}

O espaço cibernético, diferente do estatal, ultrapassa fronteiras e envolve uma rede mundial compartilhada globalmente. Nesse sentido, conforme Medeiros Filho (20I4), esse ambiente demanda novos arranjos de governança global, dentre os quais a discussão sobre um regime internacional para a discussão do tema.

Apesar de a questão cibernética não respeitar fronteiras políticas, constatamos que no espaço Sul-Americano ainda é tratada prioritariamente no interior das fronteiras dos estados-nações, como um assunto doméstico.

Pelas análises dos documentos, constatamos que tem havido esforços, por parte de organismos da OEA e do Conselho de Defesa Sul-Americano (CDS), dois fóruns regionais nos quais participam os países em análise, para estabelecer políticas relativas ao espaço cibernético.

Algumas iniciativas, como os Planos de Ação de 2012 e de 2013 (UNASUL), que propôs a criação de um Grupo de trabalho para avaliar a viabilidade de estabelecer políticas e mecanismos regionais a fim de fazer frente às ameaças cibernéticas ou informáticas no âmbito da defesa são exemplos, todavia ainda não existe uma efetividade nas políticas promovidas, no sentido de criar uma conformação regional, ainda que também não foi constatado o ressuscitar de uma velha agenda nas relações de poder, tendo no espaço cibernético o catalisador de possíveis entraves que levem a litígios cibernéticos entre os Estados. 
Os três países analisados tendem a priorizar o enfoque nacional em seus documentos e essa preferência pelo tratamento doméstico se justifica na medida em que o país precisa garantir inicialmente sua soberania nacional. Enquanto não finalizam a organização da defesa e segurança cibernética no cenário nacional, os países sul-americanos procuram atender algumas diretrizes dos fóruns regionais e buscam algum nível de aproximação por meio da cooperação bilateral entre países.

Cabe destacar um aspecto positivo nas políticas analisadas com relação à questão cibernética: são relativamente recentes e estão em processo de implantação, assim como suas respectivas estruturas, o que facilita o debate sobre o aprofundamento na conformação e cooperação entre os países.

Em suma, este artigo procurou apresentar um breve esboço das políticas de defesa e segurança voltadas ao espaço cibernético em três países da América do Sul: Argentina, Brasil e Colômbia e situá-los no âmbito de dois fóruns regionais (OEA e UNASUL). Todavia, não tivemos a pretensão de exaurir o assunto, haja vista a sua complexidade e necessidade de maior aprofundamento.

\section{REFERÊNCIAS}

Argentina. Ministerio De Defensa. 2015. Decisíon Administrativa 15/2015. Buenos Aires: InfoLeg.

Bonilla, Javier. Centro de Ciberdefensa Militar en Uruguay. Defense.com. Seção Uruguay. Madrid, set. 20I3. Accessed May IO, 20I6. http:// www.defensa.com/frontend/defensa/centro-ciberdefensa-militaruruguay-vnioooo-vst342

Brasil. 20I2. Livro Branco de Defesa. Brasília: Ministério da Defesa.

Brasil. 2013. Política Nacional de Defesa. Brasília: Ministério da Defesa.

Brasil. 20Iza. Declaración de Buenos Aires de los Ministros de Defensa del Brasil y Argentina. Brasília: Ministério da Defesa. Accessed May ıо, 2016. http://www.defesa.gov.br/arquivos/2013/meso9/comunicado.pdf.

Brasil. 20I5. Estratégia de segurança da informação e comunicações e de segurança cibernética da administração pública federal 2015-2018. Brasília: GSI.

Bustamante, Gilberto Aranda, Jorge Riquelme Rivera and Sergio Salinas Cañas. 20I5. "La ciberdefensa como parte de la agenda de integración sudamericana". Línea Sur 9. Revista de Política Exterior. Accessed May IO, 20I6. http://sedici.unlp.edu.ar/bitstream/handle/ıO9I5/40I84/ 
A geopolítica do espaço cibernético Sul-americano: (in) conformação de políticas de segurança e defesa cibernética?

Documento_completo.pdf?sequence=I

Carou, Heriberto Cair . 2002. "El retomo de la geopolítica: nuevos y viejos conflictos bélicos". Sociedad y Utopía. Revista de Ciencias Sociales, n.I9, Mayo. Madrid, España.

Carvalho, Paulo Sergio Melo de. 20II. "Conferência de Abertura: o setor cibernético nas forças armadas brasileiras”. In Desafios estratégicos para segurança e defesa cibernética, organized by Otávio Santana Rêgo Barros. Brasília: Secretária de Assuntos Estratégicos da Presidência da República.

Chile. 2oro. Libro de la Defensa Nacional. Santiago: Ministerio de Defensa Nacional.

Chile. 20I4. Orden Ministerial $n^{\circ}$ 3.380. Estado Mayor Conjunto. Santiago: Ministério de Defensa Nacional.

Colômbia. Mintic. 20I5. Colombia y Corea desarrollan primera etapa del programa de cooperación em TIC. Bogotá: Governo da Colômbia. Accessed Feb I2, 20I8, http://www.mintic.gov.co/portal/604/w3-article-954I. html,

Conpes. 20Ir. "Lineamientos de Política para Ciberseguridad y Ciberdefensa.” Documento 370I. Bogotá: Departamento Nacional de Planeación.

Contardo, Andrés Polloni . 2015. "Ciberseguridad: Estamos preparados". Revista Escenários Actuales, Ano 20, no. I. Chile: CESIM.

Dagnino, Renato et al . 2002: Gestão Estratégica da Inovação: metodologias para análise e implementação. Taubaté: Ed. Cabral Universitária.

El Tiempo. "Colombia y Brasil profundizan cooperación en la frontera". Bogotá, jan. 20I2. Accessed Feb I2, 20I8. http://www.eltiempo.com/archivo/documento/CMS-I0955537.

Equador. 20I4. Agenda Politica de la Defensa . 2014-2017. Quito: Ministerio de Defensa Nacional.

Equador. 2008. Agenda Nacional de Seguridad Interna y Externa. Quito: Ministerio Coordinador de Seguridad Interna y Externa.

França. 20I5. French National Digital Security Strategy. Paris: ANSSI.

França. 2013. White Paper on Defence and National Security. Paris: Ministére de la Défense.

Ferreira Neto, Walfredo Bento . 20I4. "Territorializando o "novo" e reTerritorializando os Tradicionais: a Cibernética como espaço e recurso de poder." In Segurança e Defesa Cibernética: da fronteira física aos muros virtuais, organized by Oscar Mederios Filho, Walfredo B. Ferreira Neto and Selma Lúcia de Moura Gonzalez. Coleção I - Defesa e Fronteiras

238 Austral: Revista Brasileira de Estratégia e Relações Internacionais v.7, n.14, Jul./Dez. 2018 
Cibernéticas Pernambuco: Editora UFPE.

Gsi. 20I7. Missão do DSIC. Brasília: DSIC. Accessed May I2, 20I7. http://dsic. planalto.gov.br/missao-do-dsic

Iitcup. 20I6. Missión. Bolívia: Academia Nacional de Polícias, 20I6. Accessed May I2, 20I7. http://www.iitcup.org/Mision.html.

Infodefensa. 20I5. "Ecuador pone los ojos en los sistemas en ciberdefensa brasileños”. Infodefensa. Quito, jun. 2015. Accessed May I2, 2017. http://www.infodefensa.com/latam/2015/o6/10/noticia-ecuador-sistemas-ciberdefensa-brasilenos.html

Justribó, Candela . 20I4. "Ciberdefensa: Uma visión desde la UNASUR". VII Congreso del Instituto de Relaciones Internacionales. Buenos Aires: UNLP.

Justribó, Candela, Sol Gastaldi, Sol and Jorge A. Fernández. 20I4. "Las estrategias de ciberseguridad y ciberdefensa en Argentina: marco político-institucional y normativo". Informe de Investigación. Buenos Aires: Escuela de Defensa Nacional.

Mandarino JR., Raphael and Claudia Canongia. 20I0. Livro verde: segurança cibernética no Brasil. Departamento de Segurança da Informação e Comunicações. Brasília: GSI.

Mcguire, Mike and Samantha Dowling. 2013. "Cyber crime: a review of the evidence”. Home Office Research Report 75. Reino Unido: Londres.

Medeiros Filho, Oscar. 20I4. "Em busca de ordem cibernética internacional". In Segurança e Defesa Cibernética: da fronteira física aos muros virtuais, organized by Oscar Mederios Filho, Walfredo B. Ferreira Neto and Selma Lúcia de Moura Gonzalez. Coleção I - Defesa e Fronteiras Cibernéticas Pernambuco: Editora UFPE.

Naím, Moisés. 2006. Ilícito: o ataque da pirataria, da lavagem de dinheiro e o do tráfico à economia global. Rio de Janeiro: Ed. Jorge Zahar.

OEA. ASAMBLEA GENERAL. 2003. Actas y Documentos. Volumen I. Trigésimo Tercer Período Ordinario de Sesiones. Santiago, Chile. Accessed May I2, 20I7, http://www.oas.org/es/sla/docs/AGo2290Si2.pdf.

ASAMBLEA GENERAL. 2004. Actas y Documentos. Volumen I. Trigésimo Cuarto Período Ordinario de Sesiones. Quito, Ecuador. Accessed May I2, 20I7, http://www.oas.org/es/sla/docs/ago2528so8.pdf

DEPARTAMENTO DE COOPERACIÓN JURÍDICA. 2007. Portal Interamericano de Cooperación en materia de Delito Cibernético. Accessed May I2, 20I7, http://www.oas.org/juridico/spanish/cybersp.htm 20I4. OAS Makes Public Recommendations on Cyber Security for Colom- 
A geopolítica do espaço cibernético Sul-americano: (in) conformação de políticas de segurança e defesa cibernética?

bia. Estados Unidos: Press of OEA. Accessed Feb I2, 20I8. http:// www.oas.org/en/media_center/press_release.asp?sCodigo=E-I96/I4 20I7. "Portal Interamericano de Cooperación en materia de Delito Cibernético". Accessed May I2, 20I7. http://www.oas.org/juridico/ spanish/cybersp.htm

OEA. Novena Reunión del Grupo de Trabajo en Delito Cibernético. Recomendaciones. I2 у I3 de diciembre de 20I6. Washington, D.C. Accessed May I2, 20I7. http://www.oas.org/juridico/spanish/cybersp_expertos.htm

OEA. REMJA. Recomendaciones II Reunion de Ministros de Justicia o de Ministros o Procuradores Generales de las Americas sobre Delito Cibernetico. Lima, Perú - I al 3 de Marzo de I999. Accessed May I2, 20I7, http:// www.oas.org/juridico/spanish/cybersp_reun.htm

Oliveira, Marcos Guedes de, Lucas S Portela, Walfredo Ferreira Neto, Adriana Marques, and Graciela Pagliari. 20I7. Guia de defesa cibernética na América do Sul. Recife: Ed. UFPE.

Paraguai. 20I5. Decreto $n^{\circ}$ 3.275/2015. Poder Executivo. Assunção: Ministerio de Defensa Nacional.

Paraguai. 2013. Primer Libro Blanco de la Defensa. Assunção: Ministerio de Defensa Nacional.

Portela, Lucas Soares. 20I5. Movimentos centrais e subjacentes no espaço cibernético do século XXI. Dissertação (Mestrado em Ciências Militares, ECEME, 20I5). Rio de Janeiro

Serafim, Milena Pavan and Rafael de Brito Dias. 20I2. "Análise de Política: uma revisão da literatura". Cadernos Gestão Social o3, no. oI, jan-jun. Bahia: UFBA.

Soares, Fayga. "Brasil e Suécia realizam encontro bilateral na área de Defesa". Ministério da Defesa. Brasília, Fev. 20I6. Accessed Fev I2, 20I6, http:// www.defesa.gov.br/noticias/18286-brasil-e-suecia-realizam-encontro-bilateral-na-area-de-defesa

Unasul. Conselho de Defesa Sul-Americano (CDS). 20I2. Acta da primera reunión para la conformación de un grupo de trabajo para evaluar la factibilidad de establecer politicas y mecanismos regionales para hacer frente a las amenazas cibernéticas o informáticas en ámbito de la defesa. Lima. 2013. VII Reunión ordinaria del Consejo de Jefas y Jefes de Estado y de Gobierno de la Unión de Naciones Suramericanas. Paramaribo: UNASUL.

. Conselho de Defesa Sul-Americano (CDS). 20I4. X Reunión de la in-

240 Austral: Revista Brasileira de Estratégia e Relações Internacionais v.7, n.14, Jul./Dez. 2018 
stancia ejecutiva del Consejo de Defensa Suramericano. Cartagena. . Conselho de Defesa Sul-Americano (CDS). 20I7. Acta I Reunión Virtual Grupo de Trabajo Ciberdefensa CDS-UNASUR. Equador: CDS.

Uruguai. 20I4. Política de Defensa Nacional. Montevídeu: Ministerio de Defensa.

Uruguai. 2005. Libro Blanco de la Defensa Nacional: aportes para um debate. Montevídeu: Ministerio de Defensa Nacional.

Velázquez, Tomás. 2015. "Las Fuerzas Armadas paraguayas crean una unidad dedicada a la Guerra Electrónica". Defensa.com. Paraguai, abril. Accessed May II, 20I6. http://www.defensa.com/frontend/ defensa/fuerzas-armadas-paraguayas-crean-unidad-dedicada-guerra-vni5398-vst335

\section{RESUMO}

A proposta deste artigo é analisar as atuais políticas de segurança e defesa cibernética no âmbito dos três países sul-americanos com maior densidade de internautas - Argentina, Brasil e Colômbia, situando essas políticas no contexto de dois fóruns regionais: Organização dos Estados Americanos (OEA) e a União de Nações Sul-Americanas (UNASUL), e a possível existência de interlocução entre elas ou se está em configuração uma nova geopolítica do espaço cibernético na região que influencia na conformação de poder regional.

\section{PALAVRAS-CHAVE}

Espaço Cibernético; Geopolítica; América do Sul. 